\title{
Cartas al editor: Reflexión sobre la carta de Rafael Gutiérrez Girardot
}

Hernán Alejandro Olano García

Universidad de La Sabana, Colombia

(c) $\underset{\mathrm{Br}}{\mathrm{Br}}$ 


\section{Carta de Rafael Gutiérrez Girardot}

17 de abril de 1993

Sr. Dr.

Eduardo Ruiz Martínez

Sociedad Nariñista de Colombia

Santafé de Bogotá

Muy estimado amigo,

A mi regreso de un viaje de conferencias por Bélgica y España, encontré su carta del 2 de febrero de este año, que fue enviada 20 días después. Permítame mencionar estas circunstancias para justificar mi tardía respuesta a su carta tan generosa y honrosa.

Para un intelectual apasionadamente colombiano y apasionadamente intelectual, como lo soy, por ser colombiano e hispanoamericano, es una distinción más que honrosa ser elegido Individuo correspondiente de la Sociedad Nariñista de Colombia, que se propone rescatar la figura excepcional en la historia de nuestra patria y de nuestra América y hacerle la justicia histórica que merece. Su libro sobre la biblioteca de "Don Antonio Nariño", como se lo llama en nuestras historias patrias, ha abierto caminos para que convirtamos a "Don Antonio Nariño" en "nuestro Antonio Nariño", es decir, el de nuestra América. Sobra decirle que cuente conmigo incondicionalmente para acompañarlo en esta empresa. Es también la de una indispensable revisión de nuestra historia, que tan urgentemente necesitamos. Nos escanotearon nuestro pasado y ahora "la oligarquía de los muertos", que siempre sigue gobernándonos, nos pasa la sangrienta y destructora cuenta. Pablo Escobar no es una planta silvestre.

Mi discurso de recepción tratará sobre "Antonio Nariño, la razón desafiante".

La fecha en la que podré pronunciar ese discurso de recepción podría ser en el mes de noviembre de este año. En ese mes dictaré cursos y haré seminarios en el Colegio Mayor de Nuestra Sra. del Rosario, que es nuestra Alma mater.

En espera de sus noticias, reciba usted el saludo agradecido y cordial de su amigo,

Rafael Gutiérrez Girardot 


\section{Reflexión sobre la carta de Rafael Gutiérrez Girardot}

Apreciado señor Director:

En mi condición de Presidente de la Academia Patriótica Nacional "Antonio Nariño", Ilegaron a mi poder un buen número de documentos que luego de clasificarlos, fueron entregados en resguardo al Archivo Histórico "Cipriano Rodríguez Santamaría" de la Universidad de La Sabana, donde se conservará y será digitalizado para consulta, en el denominado "Sub fondo Antonio Cacua Prada", que custodiará la documentación de este ilustre académico.

Sin embargo, me llamó la atención y consideré conservar temporalmente para su difusión, una carta de Rafael Gutiérrez Girardot, ilustre filósofo boyacense, profesor del Romanisches Seminar der Universität Bonn, quien en carta dirigida a Eduardo Ruiz Martínez desde Alemania, fechada el 17 de abril de 1993, expresaba, en relación con su nombramiento en la Sociedad Nariñista de Colombia, que su discurso de posesión trataría sobre "Antonio Nariño, la razón desafiante" y, entre otras, agregaba las siguientes líneas de hondo significado:

"Para un intelectual apasionadamente colombiano y apasionadamente intelectual, como lo soy, por ser colombiano e hispanoamericano, es una distinción más que honrosa ser elegido Individuo correspondiente de la Sociedad Nariñista de Colombia, que se propone rescatar la figura excepcional en la historia de nuestra patria y de nuestra América y hacerle la justicia histórica que merece. Su libro sobre la biblioteca de "Don Antonio Nariño", como se lo llama en nuestras historias patrias, ha abierto caminos para que convirtamos a "Don Antonio Nariño" en "nuestro Antonio Nariño", es decir, el de Nuestra América. Sobra decirle que cuente conmigo incondicionalmente para acompañarlo en esa empresa. Es también la de una indispensable revisión de nuestra historia, que tan urgentemente necesitamos. Nos escamotearon nuestro pasado y ahora "la oligarquía de los muertos", que siempre sigue gobernándonos, nos pasa la sangrienta y destructora cuenta. Pablo Escobar no es una planta silvestre".

La carta, que lleva la firma autógrafa en tinta líquida de color azul, hace parte de esa faceta irónica sobre los nefastos personajes de la historia reciente colombiana, como es el caso de Pablo Escobar. Con ironía, Gutiérrez se refiere al narcotraficante, "entre el hombre finito y el que quiere y cree apoderarse de lo infinito, o entre el hombre mortal y el que cree saberse inmortal, o entre la conciencia y el engaño" (Gutiérrez, 2011, p. 131).

En el texto, el "cerebralismo" de Gutiérrez nos muestra la diferencia de dos mundos, el histórico de los héroes y el histórico de los anti-héroes; entre el ser y la apariencia; "entre la evidente pequeñez humana y la presunta grandeza del hombre que se siente imagen de la divinidad" (137), que es Escobar Gaviria. 
Esa desproporción entre un personaje, Precursor de nuestra Independencia y un personaje, que usa los "precursores químicos" para el procesamiento de sustancias alucinógenas, "produce el saber de un mundo insensato y de una divinidad caótica" (137), como se desarrolla la vida en este "laberinto" de la vida misma.

Precisamente, la última parte de la carta, cuando dice: "Pablo Escobar no es una planta silvestre" (Gutiérrez, 1993), tan sólo nos recuerda el propósito del ensayo interpretativo sobre Borges: "proponer a los hombres la lucidez en una era bajamente romántica" (Gutiérrez, 2011, p. 156).

Hernán Alejandro Olano García

Doctor Magna Cum Laude en Derecho Canónico

Profesor de la Universidad de La Sabana

Correo: hernan.olano@unisabana.edu.co

Twitter e Instagram: HernanOlano

Blog: hernanolano.blogspot.com

\section{REFERENCIAS}

Gutiérrez Giradot, R. (1993). Carta inédita dirigida desde Bonn a Eduardo Ruiz Martínez. Bonn: texto inédito.

Gutiérrez Giradot, R. (2011). Jorge Luis Borges: Ensayo de interpretación. Bogotá, D.C.: Ediciones B. 